\title{
Balkanologie
}

Balkanologie Revue d'études pluridisciplinaires

Vol. VII, $n^{\circ} 2$ | 2003

Volume VII Numéro 2

\section{Yves TOMIĆ, La Serbie du prince Miloš à Milošević}

Bruxelles / Bern / Berlin / Frankfurt / New York / Oxford /Wien : P. I. E.

- Peter Lang, 2003, 165 p.

\section{Diane Masson}

\section{(2) OpenEdition}

\section{Journals}

Édition électronique

URL : http://journals.openedition.org/balkanologie/1971

DOI : 10.4000/balkanologie.1971

ISSN : 1965-0582

Éditeur

Association française d'études sur les Balkans (Afebalk)

Édition imprimée

Date de publication : 1 décembre 2003

Pagination : 233

ISSN : 1279-7952

\section{Référence électronique}

Diane Masson, "Yves TOMIĆ, La Serbie du prince Miloš à Milošević », Balkanologie [En ligne], Vol. VII, n 2 | 2003, mis en ligne le 19 février 2009, consulté le 17 décembre 2020. URL : http://

journals.openedition.org/balkanologie/1971; DOI : https://doi.org/10.4000/balkanologie.1971

(c) Tous droits réservés 
ves est remis en cause, atténué, expliqué, cautionné, décrié, adopté, rejeté. L'utilisation de la formule varie encore entre descripteur d'un événement singulier et nouvelle catégorie de dénomination, même si cette dernière tendance semble se confirmer.

Travaillant sur un sujet sensible, A. Krieg-Planque s'est tenue à l'écart des partis-pris de ceux qui sont " pris dans leur moralité " et de ceux qui sont " coincés dans leur vision nationaliste ". C'est un sujet objectivé qu'elle a traité, un travail dense et minutieux qu'elle nous livre ici.

Patrick Michels

\section{Tomić [Yves] \\ La Serbie du prince Miloš à Milošević \\ Bruxelles / Bern / Berlin / Frankfurt / New York / Oxford /Wien : P. I. E. - Peter Lang, 2003, 165 p.}

L'ouvrage d'Yves Tomic comble un vide bibliographique important en France, puisqu'il retrace l'histoire de la Serbie (et non des Serbes, ce qui constitue une différence majeure) depuis le début du XIX ${ }^{e}$ siècle jusqu'à nos jours. La démarche de l'auteur, historien de formation, est de resituer les événements des deux dernières décennies du XX $\mathrm{X}^{\mathrm{e}}$ siècle en Serbie (et dans les Balkans) dans la longue durée de la " construction nationale serbe ", afin d'en permettre une meilleure compréhension.

Cinq chapitres retracent ainsi l'évolution de la Serbie : la construction nationale au XIX siècle ; la formation de l'idéologie nationale au XIX ${ }^{\mathrm{e}}$ siècle ; l'intégration nationale des Serbes dans la Yougoslavie ; la question nationale dans la Yougoslavie communiste ; du ressentiment à la guerre. La permanence de la question nationale, récurrente dans l'histoire récente serbe, s'expliquerait notamment par deux faits principaux : d'une part, la Serbie n'est jamais véritablement parvenue à consolider son propre Etat national ; de l'autre - et c'est extrêmement important pour comprendre les relations actuelles entre les Serbes de Serbie étroite et les autres Serbes (Bosnie-Herzégovine, Croatie, Kosovo) - les Serbes dans leur ensemble n'ont jamais été réunis au sein d'une même nation. Dans cet ouvrage, l'analyse des différents Etats yougoslaves depuis 1918 n'est pas négligée et l'on perçoit bien la progression de la position, parfois ambiguë, de la Serbie, ainsi que l'ouverture de la question serbe dans la Yougoslavie communiste.

Qualifié de " régime politique autoritaire " puis de dérive dictatoriale à partir de 1998, et non de totalitarisme, le système politique instauré par S. Milošević est finement étudié, bousculant un certain nombre d'idées reçues telles que le présumé soutien sans faille des citoyens serbes à leur président ou leur non résistance à sa politique, comme l'a prouvé la " révolution " du 5 octobre 2000.

l'ouvrage se termine sur un point d'interrogation quant à l'avenir de la Serbie et la capacité de ses nouveaux dirigeants à mener à bien une " transition " qui se révèle relativement chaotique, sur fond de problèmes territoriaux non résolus (Kosovo) et d'union bancale (Monténégro). 


\section{Carmichael [Cathie],}

Ethnic cleansing in the Balkans. Nationalism and the destruction of community,

London / New York : Routledge, 2002 [Bibliogr., Index], 192 p.

Pendant un temps, on a pu lire de ci de là, un nombre incroyable (et très certainement incalculable) de textes traitant ou évoquant le " nettoyage ethnique n. Plusieurs chercheurs ont tenté d'en poser une définition; d'autres d'en tirer des leçons ; certains d'établir un parti politique ; d'autres de soutenir une cause, ...

Certains ont cherché à en démontrer les mécanismes, les invariants ; d'autres ont rattaché cette idéologie à une nation particulière, pratiquant un racisme autrement vilipendé. Certains, outrés, choqués, sous le poids de l'émotion, se sont tus ; d'autres encore ont conspué. Certains ont pris le temps d'analyser ; d'autres celui de réagir ; ...

A cette époque, le plus souvent dans la presse, les " analyses " rapides permettaient l'économie d'une réflexion sur ce phénomène ; les réactions vives, les bribes d'information nous parvenant pressaient les études. C'est à cela que nombre de chercheurs ont réagi. Cathie Carmichael fait partie de ceux qui ont objectivé leur sujet d'étude. Certains pourront regretter le manque de sentimentalité nécessaire à cette pratique, d'autres se féliciteront de cette démarche scientifique.

La problématique de l'ouvrage est de " définir ce que ce terme signifie et placer les événements encadrant la pratique du nettoyage ethnique dans un contexte géographique et historique plus large ". Le nettoyage ethnique n'est pas tant un phénomène balkanique que lié au nationalisme, son présupposé étant que "les origines du nettoyage ethnique sont presqu'entièrement idéologiques ", mais qu' " en tant que phénomène, il n'est certainement pas restreint à l'Europe du sud-est, ni n'en est issu ", les origines religieuses et nationalistes de cette violence se trouvant dans la pensée et la pratique politique européennes. L'auteur s'intéresse aux actes symboliques de cruauté, ainsi qu'à la construction artificielle de la haine et de l'altérité.

C. Carmichael rappelle comment s'est déroulée l'intégration du nationalisme dans les Balkans (destruction d'une bonne partie de la tradition, avec une reconceptualisation de l'histoire et la perception de son identité comme civilisée et " non musulmane "; complication due à une différentiation axée sur la religion, langue et race étant identiques [Pomaks / Bulgares ; Serbes, Croates, Monténégrins / Musulmans] ; domination de la version centre-européenne du nationalisme ; transformation en doctrine de libération de l'oppression étrangère ; ...). Elle passe en revue les discours anti-musulmans dans les Balkans, qui s'intègrent peu à peu dans la culture populaire, bénéficiant du soutien occidental, avant de devenir une pratique violente et meurtrière. Elle évoque la mobilisation de la tradition des bandits (rebelles prêts à se soulever pour venir en aide aux chrétiens contre les musulmans) dans les guerres de dissolution, ne manquant pas de relever que l'abus de drogues et d'alcools, et la pratique du viol sont en contradiction avec cette tradition.

Elle revient sur nombre de fausses vérités qui ont été assénées. Le nettoyage ethnique a pris place là où les populations étaient profondément intégrées ; elle rappelle qu'il s'est déroulé des mini-guerres locales, que, parfois, les antipathies entre certains villages sont ressorties au grand jour (notamment en Macédoine), estimant que " les individus n'oublient pas ce qui s'est déroulé pendant la guerre et la crise et masquent leur hostilité jusqu'au moment où il leur est possible de se venger " (p. 78). Le passage à l'acte, même s'il se produit dans un sentiment de " juste vengeance ", n'empêche pas pour autant le senti- 